\title{
Field Observations and Modeling of Surfzone Sensible Heat Flux
}

\author{
JAMIE MacMahan, Ed ThORnton, Jessica Koscinski, AND QING WANG \\ Oceanography Department, Naval Postgraduate School, Monterey, California
}

(Manuscript received 4 August 2017, in final form 10 April 2018)

\begin{abstract}
Surfzone sensible heat flux $\left(H_{S, \mathrm{SZ}}\right)$ obtained through direct eddy-covariance estimates was measured at four different sandy beach sites along Monterey Bay, California. The $H_{S, \text { SZ }}$ source region is estimated from a footprint probability distribution function (pdf) model and is only considered when at least $70 \%$ of the footprint pdf occupies the surfzone. The measured $H_{S, \mathrm{Sz}}$ is 2 times the modeled interfacial sensible heat $\left(H_{S, \text { int }}\right)$ using COARE3.5. A formulation for estimating sensible heat flux from spray droplets $\left(H_{S \text {,spray }}\right)$ generated during depth-limited wave breaking is developed. The sea-spray generation function for droplet radii ranging over $0.1<r_{o}<1000 \mu \mathrm{m}$ is based on self-similar spectra of spray droplets measured from the surfzone forced by the average depth-limited breaking wave dissipation across the surfzone. However, it is shown that the size of the spume droplets that contribute to $H_{S \text {,spray }}$ is limited owing to the relatively short residence time in air as the droplets fall to the sea surface during wave breaking. The addition of the surfzonemodeled $H_{S \text {,spray }}$ to the COARE3.5 $H_{S \text {,int }}$ gives values similar to the observed surfzone $H_{S, \text { Sz }}$, highlighting the importance of depth-limited wave-breaking processes to sensible heat flux. Measured $H_{S, \mathrm{Sz}}$ values are an order of magnitude larger than simultaneous open ocean observations.
\end{abstract}

\section{Introduction}

Sensible heat flux from the surfzone was directly measured for the first time and is the focus of this paper. Simultaneously, the sensible heat flux was measured directly offshore. No models for comparison have been developed specifically for sensible heat flux in the surfzone, although numerous studies have been conducted for the open ocean. In the open ocean, sensible heat flux $\left(H_{S}\right)$ and latent heat flux $\left(H_{L}\right)$ are described by their components of interfacial and spray contributions:

$$
\begin{aligned}
& H_{S}=H_{S, \text { int }}+H_{S \text {,spray }} \text { and } \\
& H_{L}=H_{L, \text { int }}+H_{L \text {,spray }} .
\end{aligned}
$$

At the sea surface interface, the ocean and atmosphere are always exchanging sensible and latent heat owing to the air-sea temperature and humidity differences. The interfacial transport of sensible heat across the airsea surface boundary is controlled by wind speed and air-sea temperature differences given by the bulk approximation

Corresponding author: Jamie MacMahan, jhmacmah@nps.edu

$$
H_{S, \text { int }}=\rho_{a} c_{p} C_{\mathrm{H} 10} U_{10}\left(T_{w}-T_{a}\right),
$$

where $\rho_{a}$ is the density of air, $c_{p}$ is specific heat of air under constant pressure, $U_{10}$ is the wind speed at $10-\mathrm{m}$ elevation, $T_{w}$ is sea surface water temperature, and $T_{a}$ is the air temperature at $10 \mathrm{~m}$. The coefficient $C_{\mathrm{H} 10}$ is the bulk transfer coefficient for sensible heat, which is dependent upon wind and thermal stability of the surface layer (Andreas and Murphy 1986):

$$
C_{\mathrm{H} 10}=\frac{C_{\mathrm{HN} 10}\left(C_{\mathrm{D} 10} / C_{\mathrm{DN} 10}\right)^{1 / 2}}{1-k^{-1} C_{\mathrm{HN} 10} C_{\mathrm{DN} 10}^{-1 / 2} \psi_{h}(10 / L)},
$$

where $C_{\mathrm{D} 10}$ is the drag coefficient, which describes the bulk transfer of momentum, the subscript N10 refers to neutral conditions at $10 \mathrm{~m}, k$ is the von Kármán constant, and $\psi_{h}(10 / L)$ is a stability correction, which is a function of the Monin-Obukhov length $L$. In the same experiment here, the momentum flux was measured from the surfzone by MacMahan (2017). He found that $C_{\mathrm{D} 10}$ in the surfzone was approximately twice that offshore, which he hypothesized to be the result of increased roughness by foam generated by depth-limited breaking waves inside the surfzone. Subsequently, Hansen and MacMahan (2018, manuscript submitted to Bound.-Layer Meteor.) measured the geometric 
roughness of the surface $k_{j}$ within the surfzone using stereophotogrammetry. They found surfzone $k_{j}$ values were approximately twice suggested open ocean values, confirming the earlier hypothesis. These results suggest, based on Eq. (3), that the bulk transfer coefficient $C_{\mathrm{H} 10}$ is increased inside the surfzone relative to that in the open ocean.

There is a paucity of $H_{S \text {,int }}$ measurements in the surfzone. The only results available in the literature are by Tuller (1972), who determined $H_{S \text {,int }}$ as the residual of the energy budget. Therefore, $H_{S \text {,int }}$ described by Eq. (2) will be applied to the surfzone. It is pointed out that the formulations presented herein are approximations, and controversy exists over many issues describing heat fluxes (Veron 2015).

The contribution to sensible and latent heat flux by spray occurs when sea-spray droplets are released into the atmosphere. Veron (2015), in a review of ocean spray generation, identifies two basic mechanisms for spray droplets. The first occurs when bubbles are entrained into the water column during wave breaking and then rise to the surface and burst. The bursting bubbles typically occur on the backside of the breaking wave forming a foamy layer identified as a whitecap. The bursting process creates film and jet droplets. The film droplets occur when the submerged bubble forms a bubble cap protruding from the surface that bursts into a large number of small droplets ejected into air with radii $O(0.1-0.5 \mu \mathrm{m})$. When the bubble cap has burst, the resulting cavity collapses violently and a vertical jet forms that fragments into several droplets ejected into the air with radii $O(1-100 \mu \mathrm{m})$.

The second mechanism generates spume droplets. In the open ocean, droplets generated during whitecapping are due to a dynamic instability when vertical accelerations exceed the gravitation restoring force, with droplets flying off the crest vertically owing to steepening of the waves during generation by wind. When the wind speed exceeds approximately $7-11 \mathrm{~m} \mathrm{~s}^{-1}$, sufficient stress is generated to tear water from the surface of the wave crest in the form of spume with droplet radii $O(10-1000 \mu \mathrm{m}$ or greater $)$.

One of the largest uncertainties in predicting heat fluxes induced by sea-spray droplets in the open ocean is associated with the production function for spray droplets (e.g., Andreas et al. 2015; Veron 2015; Monahan et al. 2017), which is parameterized by wind speed and whitecap coverage. Andreas (1992) suggests that spraymediated fluxes can be the same order as the interfacial fluxes. The papers by Andreas (1989, 1992, 2005), Fairall et al. (1996), and Andreas DeCosmo (1999), among others, lay the foundation for the modeling of sensible heat flux by sea-spray droplets.

Although there are numerous studies of open ocean sea-spray production, there are few surfzone measurements. Monahan (1995) speculated that greater sea-spray aerosols would be generated over the surfzone than in the open ocean owing to waves continually breaking across the surfzone. Within the surfzone, spray droplets are generated during depth-limited wave breaking (van Eijk et al. 2011). Depth-limited breaking is due to kinematic instability as the speed of the wave crest exceeds the phase speed of the wave during shoaling. The crest curls forward with droplets ejected horizontally into the air. The strength of wave breaking and the amount of spray droplet generated is dependent on the type of breaking wave. Breaker type is parameterized by the surf similarity parameter $\xi=\tan \beta /\left(H_{\text {sig }} / L_{o}\right)^{1 / 2}$, where $\tan \beta$ is the beach slope, $H_{\text {sig }}$ is the significant wave height, and $L_{o}$ is the wavelength calculated for deep water (Battjes 1974). Plunging (waves that curl over) and collapsing (shore break) breaking waves are the most violent, and occur when $\xi>0.4$. Spilling breakers occur when $\xi<0.4$ and are less violent, similar to whitecapping.

Spume droplets are generated at wave crests and fall down the face of spilling breakers. As the intensity of spilling breakers increases, the crest increasingly curls over, generating greater spume. As opposed to the gentle breaking process of a spilling breaker, a plunging breaker face becomes vertical and then overturns throwing a jet of water forward composed of large spume droplets. No wind is required to generate spume in the surfzone. As the jet crashes into the surface, splashes are sent up forward of the wave as a secondary splash generating more spume droplets Derakhti and Kirby (2014). This process of jet formation and splash down can be repeated several times as the wave moves toward the shore. The waves during the experiment were mostly plunging breakers.

Both mechanisms of generated spray droplets and spume occur within the surfzone. Depth-limited wave breaking produces orders of magnitude more spray droplets than whitecapping in the open ocean. Most measurements in the surfzone have focused on aerosol production of smaller droplet radii $(<30 \mu \mathrm{m})$ that are transported inland (Neele et al. 1998; de Leeuw et al. 2000; Vignati et al. 2001; Clarke et al. 2006; Piazzola et al. 2015), and the production is parameterized as a function of wind speed.

Owing to depth-limited wave breaking in the surfzone, the correct parameterization should be related to the breaking wave. Chomka and Petelski (1997) relate the total measured droplet sea-salt production, without regard to droplet size, to the average wave dissipation in the surfzone. Van Eijk et al. (2011) relates measured production of spray over the limited range of droplet radii $0.2-10 \mu \mathrm{m}$ also to the average wave dissipation 
across the surfzone. Andreas (2016) measured spray production of larger droplets (radii $0-150 \mu \mathrm{m}$ ) from the surfzone along a rocky shoreline applying footprint analysis and found that the spectra of the sea-spray droplet radii had the same shape independent of wind speed. He concluded that the spray concentrations on a rocky shoreline are two to three orders of magnitude greater than open ocean values.

In this paper, sensible heat flux measurements across the surfzone as determined using footprint analysis are presented. The self-similar sea-spray production spectrum by Andreas (2016) is combined with the sea-spray production model by van Eijk et al. (2011) to describe spray-mediated sensible heat flux as a function of the average breaking wave dissipation within the surfzone. The combined estimates of interfacial sensible heat flux [Eq. (2)] and the sensible heat flux spray droplet model developed herein compare reasonably well to surfzone observations of $H_{S}$. The measured $H_{S}$ values are used to calibrate the developed model.

\section{Field experiment}

Collocated sonic anemometers, temperature, and relative humidity sensors were mounted on six 6-m-high towers and deployed simultaneously on four different sandy beaches located along $10 \mathrm{~km}$ of the Monterey Bay, California, shoreline (Figs. 1a,b). Towers were located on the beach at the high-tide line at each site, with an additional two towers located in the surfzone and inland beach at the southernmost site. The Monterey Bay nearshore bottom profile is composed of a relatively steep (1:7-12) foreshore beach flattening out to a low-tide surfzone terrace (1:100), continuing offshore with a steeper 1:35 offshore slope (MacMahan et al. 2010).

The location of the tower measurements is based on measuring turbulence fluxes that originate in the surfzone as determined by its footprint, which is described in detail for this experiment by MacMahan (2017). The footprint represents the source location where the measured turbulence and heat originates. The footprint cross-shore length increases with increasing stability, which determines vertical mixing, and wind speed and measurement elevation, which determine trajectory. The data were filtered based on criteria that the percent contribution of the surfzone source region exceed $70 \%$ of the total footprint. Since only times of onshore winds are considered, the footprint of turbulent fluxes originating in the surfzone required the towers be located downwind on the beach.

Observations were obtained continuously for four weeks in May-June 2016 and divided into 15-min blocks for analysis. The analysis for computing momentum fluxes and procedures for quality controlling the data are given in Aubinet et al. (2012). The sensible heat flux was computed from the sonic anemometer measurements by

$$
H_{s}=\bar{\rho}_{a} c_{p}\left\langle w^{\prime} \theta_{s}^{\prime}\right\rangle
$$

where $w^{\prime}$ is the turbulent vertical velocity, $\theta_{s}^{\prime}$ is temperature perturbation, $\bar{\rho}_{a}$ is the average $(15 \mathrm{~min})$ air density, and angle brackets denote the 15-min time average. Direct estimates of $H_{L}$ were not obtained.

Waves along with ocean temperatures were measured using a pressure sensor and temperature string deployed in 10-m water seaward of each beach tower. Significant wave height $\left(H_{\text {sig }}\right)$, average wave period $\left(T_{\mathrm{avg}}\right)$, and wave setup were estimated from the pressure observations (Dean and Dalrymple 1984). The tower position and elevation and beach profile were surveyed with GPS. The distance between the waterline and tower location including wave setup was estimated for each $H_{S}$ measurement. Wave heights $H_{\text {sig }}$ ranged from 0.13 to $1.2 \mathrm{~m}$ with a mean of $0.8 \mathrm{~m}$. The quantity $T_{\text {avg }}$ ranged from 6 to $13 \mathrm{~s}$ associated with local storm-generated events. The surf similarity parameter ranged from 0.3 to 0.8 with an average of 0.6 , indicating mostly plunging breakers, which was verified by observation.

Mean wind speed measured at 6-m elevation $U_{6}$ ranged from 0 to $11 \mathrm{~m} \mathrm{~s}^{-1}$, with a mean of $6 \mathrm{~m} \mathrm{~s}^{-1}$. The maximum winds occurred in the late afternoon and reduced to near zero at night. A diurnal cycle was observed that was occasionally modified by larger mesoscale atmospheric storm events.

Beach air temperature $T_{a}$ ranged from $12^{\circ}$ to $17^{\circ} \mathrm{C}$ with a mean of $14^{\circ} \mathrm{C}$. Near-surface $(<1 \mathrm{~m}$ below the surface) water temperatures also ranged from $12^{\circ}$ to $17^{\circ} \mathrm{C}$ with a mean of $16^{\circ} \mathrm{C}$. The difference of air and water temperatures $\Delta T$ ranged from $-3^{\circ}$ to $1.3^{\circ} \mathrm{C}$ and was predominantly negative, implying the atmosphere behaved as an unstable system with transfer of heat to the atmosphere. The relative humidity averaged $85 \%$. Owing to the limitations of available empirical formulations to raise $U_{6}$ measured winds to $U_{\mathrm{N} 10}$ neutral stability winds used in comparing results, momentum flux data are limited to atmospheric stabilities $(\psi)$ in the range $-2<$ $\psi<0.5, U_{6}>3 \mathrm{~m} \mathrm{~s}^{-1}$, and to onshore wind directions that are $\pm 40^{\circ}$ relative to shore normal. These limitations reduced the analyzed data to 3031 onshore records, of which 630 records are represented by the surfzone.

In addition to the beach tower measurements, open ocean $H_{S}$ was measured from a moving vessel using similar instrumentation. The vessel moved throughout Monterey Bay for most of the tower operation. The heat flux observations are taken as representing the open 


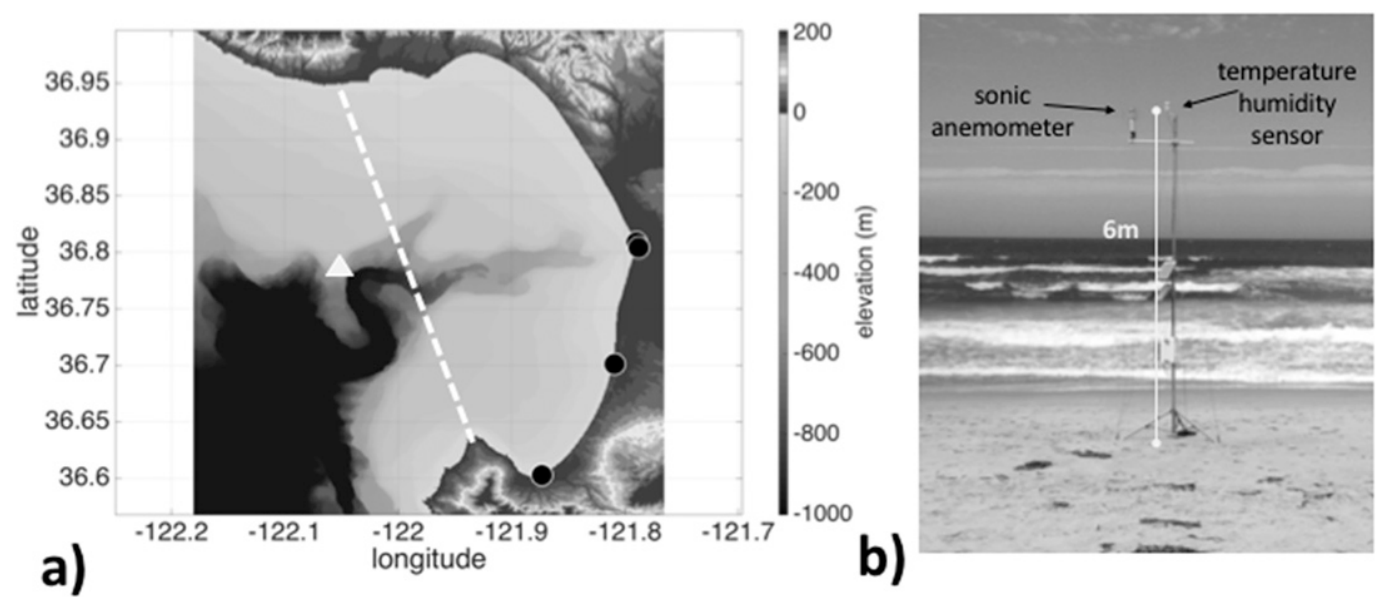

FIG. 1. (a) Topographic and bathymetry map of Monterey Bay. Black dots represent the four beaches on which six towers were deployed. The white triangle represents the NDBC buoy. The dotted white line denotes the outer boundary of Monterey Bay. (b) Sonic anemometers were collocated with temperature-humidity sensors located on top of the tower, solar panels were located in the middle, and the data acquisition system was located in the white box near the bottom. Towers were deployed at the high-tide line, where the tower base was approximately $1.2 \mathrm{~m}$ MSL.

ocean, and hence are referred to as $H_{S, \mathrm{O}}$. The vessel operation was limited to daytime hours and to lower wind conditions for safety concerns, resulting in 457 overlapping vessel and surfzone observations that are the basis of the analysis.

\section{Surfzone sensible heat flux spray model}

Winds during the experiment were generally mild and less than $11 \mathrm{~m} \mathrm{~s}^{-1}$ such that they generated minimal spume. Hence, it is assumed that the spray droplets are all generated by the breaking waves and that the air turbulence was insufficient to elevate the droplets. Therefore, spume droplets generated at the crest of a breaking wave are assumed to fall to the water surface as in quiescent air turbulence. A droplet with initial radius $r_{o}$ generated at the crest of a breaking wave has a flight time

$$
\tau_{f}=\frac{h}{u_{f}\left(r_{o}\right)},
$$

where $u_{f}$ is the Stokes fall velocity modified to account for larger Reynolds numbers owing to turbulence that characterize the fall of the larger spray droplets, and $h$ is the flight distance of the droplets with mean radius $r_{o}$ (Andreas1990; Veron 2015). For plunging breakers, the flight distance $h=K H_{\text {sig }}$, where $H_{\text {sig }}$ is the significant wave height of the depth-limited breaking waves and $K$ ranges from 0.5 for the initial fall from the crest to the wave face where the droplets enter the water at the approximate mean water level to a value of 1 or more to account for splash up of the plunging breaker.
A spray droplet rapidly exchanges sensible heat with the atmosphere as it falls, and cools to a constant evaporation temperature $T_{\mathrm{ev}}$ below the air temperature to warm the atmosphere, which differs slightly form the wet bulb temperature (Andreas 1995). The quantity $T_{\mathrm{ev}}$ is a function of the salinity of the water droplet and relative humidity of the air. This exchange of sensible heat occurs in time $\tau_{T}$ and is modeled based on microphysical equations of sea-spray evolution by Andreas $(1989,1992,1995)$

$$
\frac{T(t)-T_{\mathrm{ev}}}{T_{w}-T_{\mathrm{ev}}}=\exp \left(-\frac{t}{\tau_{T \mathrm{ev}}}\right),
$$

where $\tau_{T \mathrm{ev}}$ is defined as the time when the right-hand side of Eq. (6) reaches $1 / e$, the $e$-folding scale. The value of $\tau_{T \text { ev }}$ is a function of droplet radius where small droplets transfer their sensible and latent faster than larger droplets. At this point, the droplet has reached thermal equilibrium with the atmosphere and has exchanged its sensible heat with the atmosphere $H_{S \text {,spray. }}$ Up to this point, the droplet has retained most of its water mass.

Subsequently, the droplet will start to evaporate giving off water vapor in the process of extracting latent heat from the atmosphere $H_{S \text {,spray. }}$ However, the evaporation process is much slower, occurring in characteristic time $\tau_{r}$, which is the time scale required for an initial droplet of radius $r_{o}$ to reach moisture equilibrium with its environment while losing a significant amount of its water mass via evaporation, given by

$$
\frac{r(t)-r_{\mathrm{eq}}}{r_{o}-r_{\mathrm{eq}}}=\exp \left(-\frac{t}{\tau_{r}}\right),
$$


where the droplet temperature stabilizes at an equilibrium temperature $T_{\mathrm{eq}}$ when the equilibrium radius $r_{\mathrm{eq}}$ is reached after evaporation. Again, $\tau_{r}$ is the $e$-folding time when the droplet has experienced $1 / e$ of its radius change and has only the time to act during the fall of the droplet from the crest to when it enters the water surface. For example, Andreas (1995) shows that a $100-\mu \mathrm{m}$ droplet reaches its evaporation temperature $T_{\mathrm{ev}}$ in less than $1 \mathrm{~s}$, but the droplet does not show significant reduction in size caused by evaporation until after about $30 \mathrm{~s}$ and would not lose all its water at equilibrium temperature $T_{\text {eq }}$ until more than $500 \mathrm{~s}$, well after it had fallen into the water.

The quantity $H_{S \text {,spray }}$ is dependent on relative humidity and radius of the droplet. The evaporation of the droplet cools the atmosphere by $H_{L \text {,spray }}$ such that the net spray-mediated sensible heat flux is $H_{S \text {,spray }}-$ $H_{L \text {,spray. }}$ However, the time scales for these processes are very different, resulting in the processes being essentially independent (Veron 2015). The $H_{L \text {,spray }}$ may be ignored for $\tau_{f}<\tau_{r}$ since there is not time to exchange a significant amount of latent heat before the droplet falls back into the sea. For the average wave height during the experiment, $H_{\text {sig }}=0.8 \mathrm{~m}, \tau_{f}<\tau_{r}$ for $r_{o} \geq 20 \mu \mathrm{m}$.

For the nominal environmental conditions during the experiment, the characteristic time scales $\tau_{f}$ for the range of wave heights $(0.13-1.2 \mathrm{~m}) \tau_{T \mathrm{ev}}$ and $\tau_{r}$ for sea temperatures $\left(12^{\circ}-20^{\circ} \mathrm{C}\right)$ with a constant temperature difference between air and water $\Delta T=-2^{\circ} \mathrm{C}$, salinity of $34 \mathrm{psu}$, and relative humidity range of $75 \%-95 \%$ are plotted as a function of $r_{o}$ in Fig. 2. Veron (2015) points out that for larger spume droplet when $\tau_{f}<\tau_{r}$ the droplets will not reach thermal equilibrium before they fall back into the water. The spume droplets then will not reach $T_{\text {eq }}$, and $T_{\text {ev }}$ is the temperature scale that measures the amount of sensible heat exchanged. The criteria $\tau_{f}<\tau_{r}$ when there is not time to exchange latent heat before falling back into the ocean occurs at approximately $r_{o} \geq 20 \mu \mathrm{m}$ for these experiments (left vertical dashed line in Fig. 2). At the other end of the spectrum for the largest spume droplets, when $\tau_{f}<\tau_{T \mathrm{ev}}$, the droplets fall back into the ocean before having time to exchange all their sensible heat, which occurs at approximately $r_{o} \geq 200-400 \mu \mathrm{m}$ (right vertical dashed line in Fig. 2). For higher waves, the flight times $\tau_{f}$ are greater and the $r_{o}$ criteria are greater (see discussion section).

Andreas (1992, 2005) developed spray-mediated sensible and latent heat flux as a function of initial droplet radius $r_{o}$ :

$$
\begin{aligned}
Q_{S, \text { spray }}\left(r_{o}\right)= & \rho_{w} c_{w}\left(T_{w}-T_{\mathrm{ev}}\right)\left[1-\exp \left(-\frac{\tau_{f}}{\tau_{T \mathrm{ev}}}\right)\right] \\
& \times\left(\frac{4 \pi r_{o}^{3}}{3} \frac{d F}{d r_{o}}\right) \quad \text { and }
\end{aligned}
$$

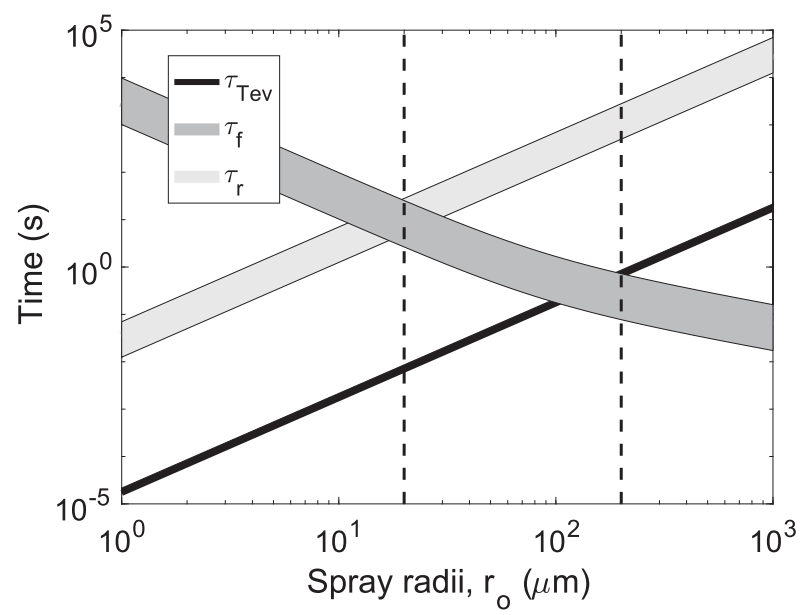

FIG. 2. Characteristic droplet $e$-folding times to reach evaporation temperature $\tau_{T \text { ev }}$ (black line) equilibrium temperature $\tau_{r}$ (light gray band), and droplet fall time $\tau_{f}$ (darker gray band) as a function of spray radii $r_{o}$. The $\tau_{T \text { ev }}$ is for a range of seawater temperatures $T_{w}=12^{\circ}-20^{\circ} \mathrm{C}$ with a constant temperature difference between water and air $\Delta T=2^{\circ} \mathrm{C}$, salinity of $34 \mathrm{psu}$, and relative humidity range of $75 \%-95 \% ; \tau_{f}$ values are for range of wave heights $0.13-1.2 \mathrm{~m}$ (adapted after Veron 2015). Left vertical dashed line: $\tau_{f} \leq \tau_{r}$. Right vertical dashed line: $\tau_{f} \leq \tau_{T \mathrm{ev}}$.

$Q_{L, \text { spray }}\left(r_{o}\right)=-\rho_{w} L_{v}\left\{1-\left[\frac{r\left(\tau_{f}\right)}{r_{o}}\right]^{3}\right\}\left(\frac{4 \pi r_{o}^{3}}{3} \frac{d F}{d r_{o}}\right)$,

where $\rho_{w}$ is density of seawater, $c_{w}$ is specific heat of seawater, $T_{w}$ is initial seawater temperature, and $T_{a}$ is air temperature. The minus sign in Eq. (8b) means that the spray droplets are extracting heat from the air if they are evaporating. The term $d F / d r_{o}$ is the sea-spray generation function (SSGF), where $\left(4 \pi r_{o}^{3} / 3\right) d F / d r_{o}$ is the rate at which the volume of droplets is produced. Equation (8b), divided by the latent heat of evaporation of water $L_{v}$, is the mass of water droplets in the air during their flights. The term in the square brackets in Eq. (8a) is a magnitude function that limits sea-spray droplet contributions to the sensible heat flux.

Van Eijk et al. (2011) evaluated the depth-limited wave-breaking SSGF that originates within the surfzone. They measured the difference in aerosol spray concentrations upwind and downwind of the surfzone for the range of $r_{o}$ from 0.1 to $10 \mu \mathrm{m}$. Their SSGF is dependent on average breaking wave dissipation $D$, parameterized on wave height (Thornton and Guza 1983):

$\frac{d F}{d r_{o}}=\left(2 r_{o}\right)^{c} 10^{a\left(1-D^{b}\right)} \quad$ for $\quad 0.1<r_{o}<10 \mu \mathrm{m}$,

where $a=10, b=-0.35$, and $c=-1.5$ are coefficients that possess units. Units of $d F / d r_{o}$ are $\mu \mathrm{m}^{-1} \mathrm{~m}^{-2} \mathrm{~s}^{-1}$. 
Andreas (2016) measured spray concentration and the rate of spray production using a cloud-imaging probe (CIP) mounted on a tower at an elevation of $8.7 \mathrm{~m}$ above mean sea level located $50-75 \mathrm{~m}$ shoreward of the surfzone on a rocky shoreline. The CIP continuously measured spray concentrations in 12 radius bins, each $12.5 \mu \mathrm{m}$ wide, from 0 to $150 \mu \mathrm{m}$. The measurements include spume generation. Footprint analysis suggested that all measured droplets came from the surfzone. It was found that the shape of the concentration spectra as a function of spray radii $r_{o}$ did not change with respect to wind speed, that is, the spectra are self-similar for different forcing. A common assumption is that the shape of the SSGF is universal, whereas the magnitude depends only on forcing parameters (e.g., Monahan et al. 1986; Andreas 1992, 2016; Wan et al. 2017),

$$
\frac{d F}{d r_{o}}=g(D) f\left(r_{o}\right)
$$

where $g(D)$ is the magnitude of the forcing function and $f\left(r_{o}\right)$ is a shape function describing the self-similar droplet size spectrum (Andreas 2016):

$$
\begin{aligned}
f\left(r_{o}\right)= & \exp \left\langle-4.20-4.09\left\{\left(\ln r_{o}-4.10\right)\right.\right. \\
& \left.\left.+\left[0.30\left(\ln r_{o}-4.10\right)^{2}+0.0078\right]^{1 / 2}\right\}\right\rangle,
\end{aligned}
$$

where $f\left(r_{o}\right)$ is normalized for the value $r_{o}=6.25 \mu \mathrm{m}$; that is, $f\left(r_{o}=6.25 \mu \mathrm{m}\right)=1$. The shape function is composed of two power-law slopes (Fig. 3) that have been combined as a hyperbola in Eq. (11).

The volume spray production spectrum represents the volume of droplets generated as a function of droplet size and is obtained by multiplying the shape function by the volume of the droplets:

$$
f_{V}\left(r_{o}\right)=\frac{4}{3} \pi r_{o}^{3} f\left(r_{o}\right)
$$

The quantity $f_{V}$ is plotted (Fig. $4 \mathrm{a}$ ) in linear dimensions to emphasize the sharp increase and then rapid decrease that limits the contribution by larger spume droplets. A maximum value occurs at $r_{o}=60 \mu \mathrm{m}$. In multiplying by $r_{o}^{3}$ in Eq. (12), the slopes of the shape function spectrum are increased by a factor of 3 .

Total spray-mediated heat fluxes are obtained by integrating over the range of droplet sizes,

$$
H_{S, \text { spray }}=\int_{r_{1}}^{r_{2}} Q_{S}\left(r_{o}\right) d r_{o} \quad \text { and }
$$

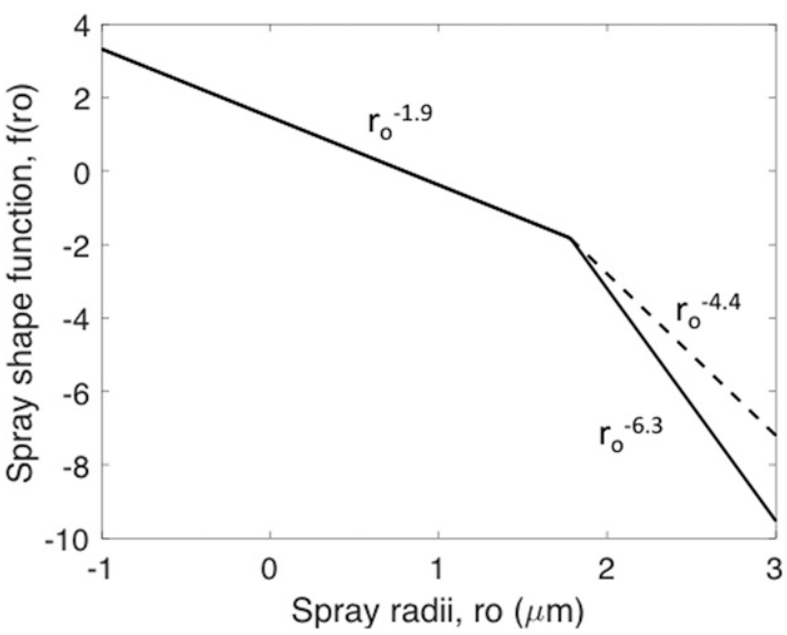

FIG. 3. Self-similar spectrum of sea-spray droplets $f\left(r_{o}\right)$ (after Andreas 2016; solid line) and Andreas (2016) modified to fit data (dashed line).

$$
H_{L, \text { spray }}=\int_{r_{1}}^{r_{2}} Q_{L}\left(r_{o}\right) d r_{o}
$$

where $r_{1}$ and $r_{2}$ represent the lower and upper limit of the droplet radii (Andreas 1992). The net spraymediated sensible heat flux is $H_{S \text {,spray }}-H_{L \text {,spray. }}$ However, the $H_{L \text {,spray }}$ was found to only contribute for $r_{o}<$ $20 \mu \mathrm{m}$, which represents less than $5 \%$ of $f_{V}$ (Fig. $4 \mathrm{c}$ ). Therefore, for simplicity $H_{L \text {,spray }}$ is neglected in calculating total sensible heat flux.

Andreas (2016) assumed that the magnitude function $g$ was dependent on wind speed. Here, it is assumed that $g(D)$ is a function of the average breaking wave dissipation across the surfzone $D$. The surfzone observations by van Eijk et al. (2011) that the SSGF as a function of breaking wave dissipation over the limited range $0.2-10 \mu \mathrm{m}$ fortuitously included $r_{o}=6.25 \mu \mathrm{m}$ that is used to normalize the Andreas (2016) shape function, which is used to define the magnitude function

$g\left[D\left(r_{o}=6.25 \mu \mathrm{m}\right)\right]=[2(6.25)]^{c} \times 10^{a\left(1-D^{b}\right)}$,

with units $\mu \mathrm{m}^{-1} \mathrm{~m}^{-2} \mathrm{~s}^{-1}$. Substituting Eqs. (12) and (14) into Eq. (10) and then into Eq. (13a) and integrating across the range of radii,

$$
\begin{aligned}
H_{S, \text { spray }}= & \rho_{w} c_{w}\left(T_{w}-T_{\text {ev }}\right)[2(6.25)]^{c} 10^{a\left(1-D^{b}\right)} \\
& \times \int_{r_{o 1}}^{r_{o 2}}\left\{\left[1-\exp \left(-\frac{\tau_{f}}{\tau_{T \mathrm{ev}}}\right)\right] f_{V}\left(r_{o}\right)\right\} d r_{o} \times 10^{-18},
\end{aligned}
$$


(a)
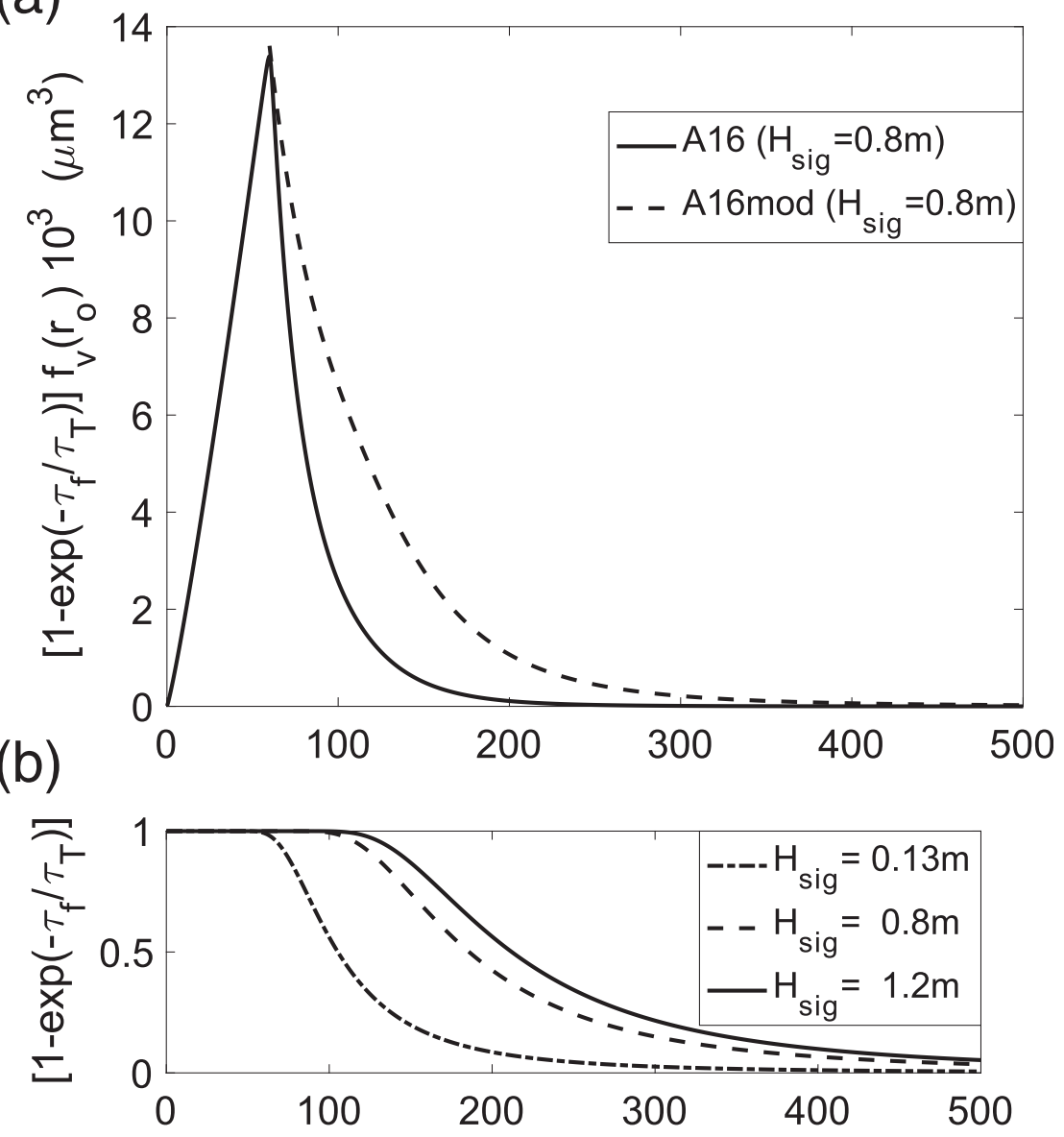

(c)

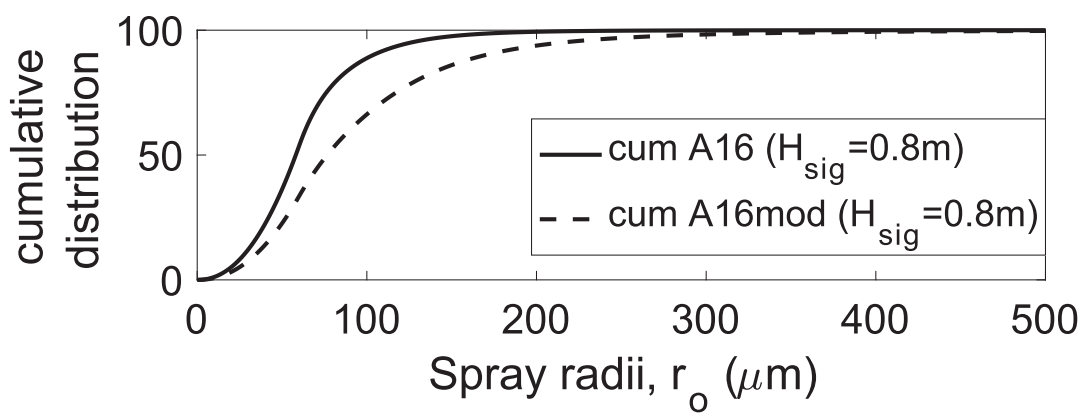

FIG. 4. (a) Volume $f\left(r_{o}\right)$ multiplied by the magnitude function of Andreas (2016; solid line) and modified version to fit data (dashed line). The $f_{V}\left(r_{o}\right)$ maximum occurs at $r_{o}=60 \mu \mathrm{m}$. (b) Magnitude function in the sensible heat flux Eq. (15) for $H_{\text {sig }}=0.13$ (broken line), 0.8 (dashed line), and 1.2 (solid line) $\mathrm{m}$ and $T_{a}=14^{\circ} \mathrm{C}$. (c) Cumulative distributions for spectra (solid black) in (a) and also multiplied by magnitude function (dashed black) in (b) for $H=0.8 \mathrm{~m}$. Calculations are for $r_{o}=0-1000 \mu \mathrm{m}$.

where the limits of integration extend the range of spray droplets radii from 0.1 to $1000 \mu \mathrm{m}$. The units for $H_{S \text {,spray }}$ are watts per meter squared.

The average breaking wave dissipation $D$ is calculated using the wave energy flux transformation model by Thornton and Guza (1983),

$$
\frac{d E(H, T) C_{g}(h, T)}{d x}=\varepsilon_{b}(H, h, T),
$$

where individual waves are described by a Rayleigh wave height distribution parameterized by the significant wave height $H_{\text {sig }}$, with the mean incident wave 
energy $E=1 / 16 \rho g H_{\text {sig }}^{2} ; C_{g}$ is the group velocity, and $\varepsilon_{b}$ is the averaged local breaking wave dissipation. Assuming normally incident waves (good assumption for experiment locations) and negligible wave reflection, the energy flux $E C_{g}$ is conserved up to breaking outside the surfzone. Therefore, the measured waves in $10-\mathrm{m}$ water depth are well before breaking and are used to specify the energy flux. Only the depth-limited breaking waves contribute to dissipation with larger waves breaking further offshore. An empirical dissipation function is used to describe the breaking wave height distribution as a function of depth [see Thornton and Guza (1983) for details]. As the waves shoal and break, the mean wave energy first decreases slightly and then increases to a maximum before significant wave breaking, and then decreases shoreward as the waves break and dissipate across the surfzone. The total breaking wave dissipation is calculated by integrating across the surfzone:

$$
E C_{g}=\int_{x_{b}}^{0} \varepsilon_{b} d x,
$$

where the outer edge of the surfzone $x_{b}$ is defined at the location where the averaged shoaling/breaking waves are maximum, and the inner limit zero is the shoreline. Hence, $x_{b}$ is equal to the average width of the surfzone. The average dissipation is given by

$$
D=E C_{g} / x_{b} .
$$

\section{Results and discussion}

The average breaking wave dissipation $D$ for the range of $H_{\text {sig }}$ from 0.13 to $1.3 \mathrm{~m}$ during the experiment ranged from 4 to $113 \mathrm{~W} \mathrm{~m}^{-2}$ with a mean of $60 \mathrm{~W} \mathrm{~m}^{-2}$. Values of $H_{S \text {,spray }}$ as a function of $D$ values during the experiment are shown in Fig. 5. A sensitivity analysis finds that a $\pm 20 \%$ error in average dissipation $D$ results in an approximate error from $+70 \%$ to $-40 \%$ in

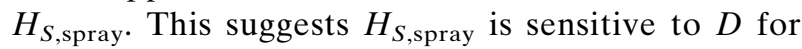
this model.

The observations of $H_{S, \mathrm{SZ}}$ are larger than $H_{S, \mathrm{O}}$, implying that the surfzone produces greater sensible heat flux, which is hypothesized to be related to the increased spray contribution by breaking waves as well as generally warmer nearshore waters for this site (Fig. 6). A significant number of $H_{S, \mathrm{SZ}}$ values occur for near-zero values of $H_{S, \mathrm{O}}$, which demonstrates that even in low winds over the ocean there is significant $H_{S, \mathrm{SZ}}$ owing to depth-limited breaking waves in the surfzone.

Surfzone $H_{S, \text { SZ }}$ observations are compared with the COARE3.5 $H_{S \text {,int }}$ estimates (Fig. $7 \mathrm{a}$ ). The $H_{S, \text { sz }}$ and
$H_{S \text {,int }}$ are linearly correlated at the $95 \%$ significance level $\left(r^{2}=0.63\right)$ with a linear regression slope of 0.46 . This suggests that about $50 \%$ of the surfzone contribution to $H_{S \text {,Sz }}$ was owing to $H_{S \text {,int }}$. Modeled $H_{S \text {,spray }}$ [Eq. (15)] added to modeled $H_{S \text {,int }}$ [Eq. (2)] is referred to as $H_{S \text {,int }+ \text { spray }}$. The modeled $H_{S, \text { int }+ \text { spray }}$ is linearly correlated with $H_{S, \mathrm{SZ}}$ at the $95 \%$ significance level $\left(r^{2}=\right.$ 0.7 ) with a linear regression slope of 0.79 (Fig. 7b). The total sensible heat flux in the surfzone was composed of near-equal contributions by interfacial and spraymediated fluxes.

Andreas (1992) and Andreas and DeCosmo (1999) suggest that spray droplet contributions to the sensible heat flux in the open ocean start to become important when $U_{10}>12 \mathrm{~m} \mathrm{~s}^{-1}$, and at $20 \mathrm{~m} \mathrm{~s}^{-1}$ are as important as interfacial heat flux contributions. Here, spray droplet contribution to heat flux is important starting at the lowest wind speeds considered $\left(U_{6}>3 \mathrm{~m} \mathrm{~s}^{-1}\right)$ because the generation of spray droplets by depth-limited breaking in the surfzone is not directly dependent on wind speed. However, it is noted that some wind is necessary for the sensible heat released by the droplets within the surfzone to reach the measurement location on the beach.

When depth-limited breaking occurs, a large range of spume droplet sizes can be generated up to $10 \mathrm{~mm}$ and greater. However, the size of spume droplet radii generated by depth-dependent breaking waves that contributes to the sensible and latent heat flux is dependent on the wave height. As the droplet generated at the wave crest falls, it has a limited amount of time to give off sensible

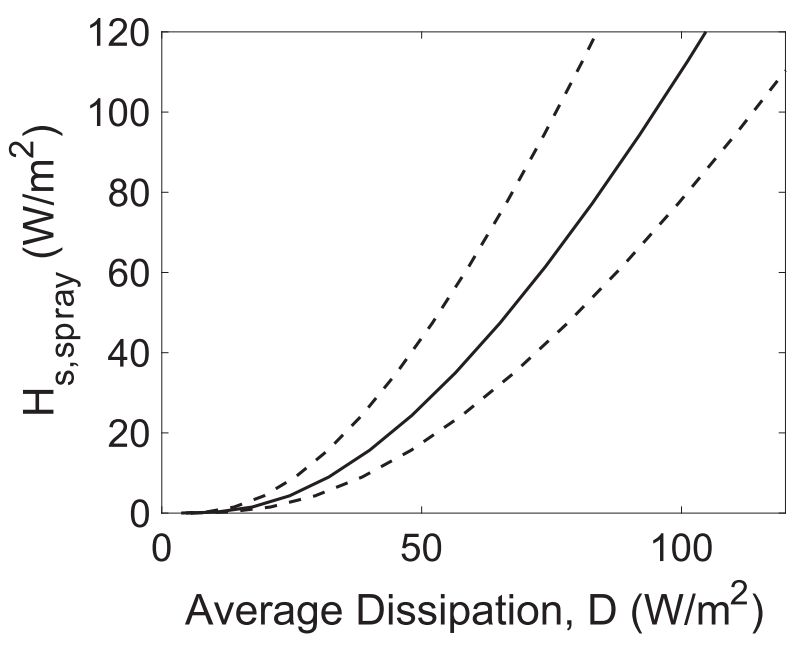

FIG. 5. Calculated sensible heat flux for sea-spray droplets $H_{S \text {,spray }}$ as a function of average breaking wave dissipation for the wave heights during the experiment $\left(H_{\text {sig }} \leq 1.3 \mathrm{~m}\right)$ for $T_{w}=$ $16^{\circ} \mathrm{C}$ and $T_{a}=14^{\circ} \mathrm{C}$. The $\pm 20 \%$ error for $D$ is shown by the dashed lines. 


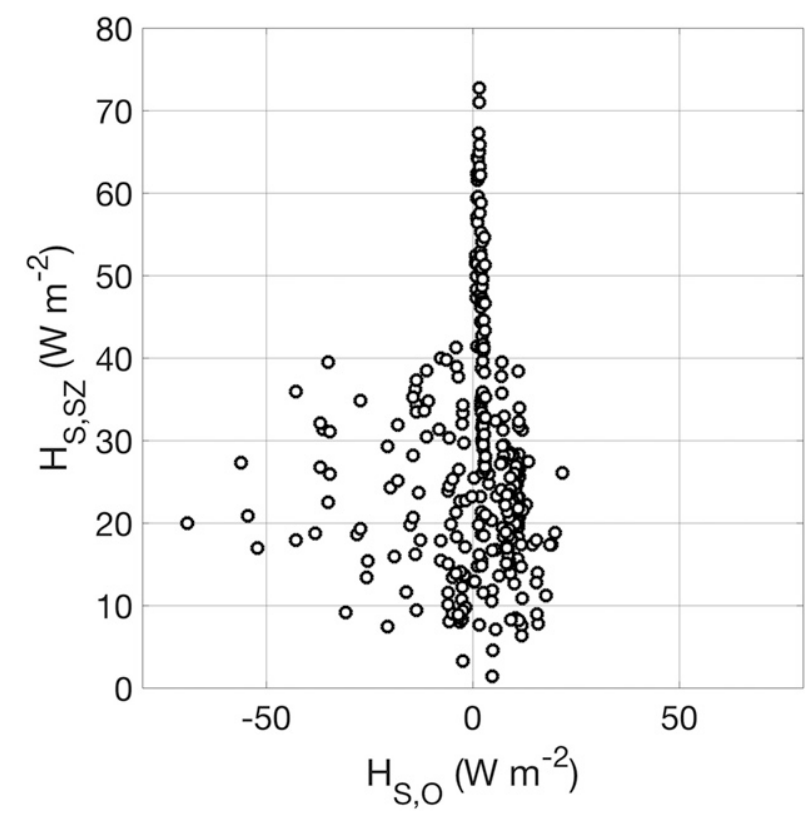

FIG. 6. Observations of surfzone sensible heat flux $\left(H_{S, \mathrm{sz}}\right)$ compared with open ocean sensible heat flux $\left(H_{S, \mathrm{O}}\right)$ observed at the same time.

and latent before reaching the water surface. For the smaller size spray droplets, the latent heat contribution is limited by evaporation time before falling back into the sea. For conditions during the experiment, $\tau_{r}<\tau_{f}$ for only $r_{o}<20 \mu \mathrm{m}$, and the latent heat by spray droplets could be neglected. For larger spume spray droplets, the time to give off sensible heat is limited by the fall time, which is described by the magnitude function [term in square brackets in Eqs. (8a) and (15)]. The magnitude function is dependent on fall time, which in turn is a function of the wave height (Fig. 4b). Applying the criterion that the spume radii that contribute to the sensible heat are limited to $r_{o}$ values at which the cumulative distribution of the total sensible heat flux reaches $99 \%\left[r_{o}(0.99)\right]$, we find that $H_{S \text {,spray }}$ for the experiment was limited approximately to $r_{o}<400 \mu \mathrm{m}$ (Fig. 4c). For larger waves, the fall distance and time increases. Allowing a range of fall distances, $0.5 H_{\text {sig }} \leq h \leq H_{\text {sig }}$ for $H_{\text {sig }}$ up to $10 \mathrm{~m}$, the calculated $r_{o}(0.99)$ range to over $700 \mu \mathrm{m}$ (Fig. 8).

The modeled total $H_{S, \mathrm{Sz}}$ values give an $O(1)$ estimate of the measured values with a $21 \%$ underestimate. Reasons for the underestimation include errors in the SSGF composed of the spectral shape for $r_{o}$ by Andreas (2016) and the magnitude function dependent on the average breaking wave dissipation by van Eijk et al. (2011). Andreas (2016) points out that his SSGF spectrum for large spray radii $r_{o}>100 \mu \mathrm{m}$ converge to open ocean values described by a joint Monahan et al. (1986) and Fairall et al. (1994) function given in Andreas (2010). He suggested this convergence could be that the larger droplets settled out before they reached the CIP. He suggests that the spray generation function is robust for spray droplets less than $50-100 \mu \mathrm{m}$, but less certain for larger droplets. In the application to sensible heat flux by spray, all spume droplets generated by the breaking waves can contribute. However, most of the spume droplets fall
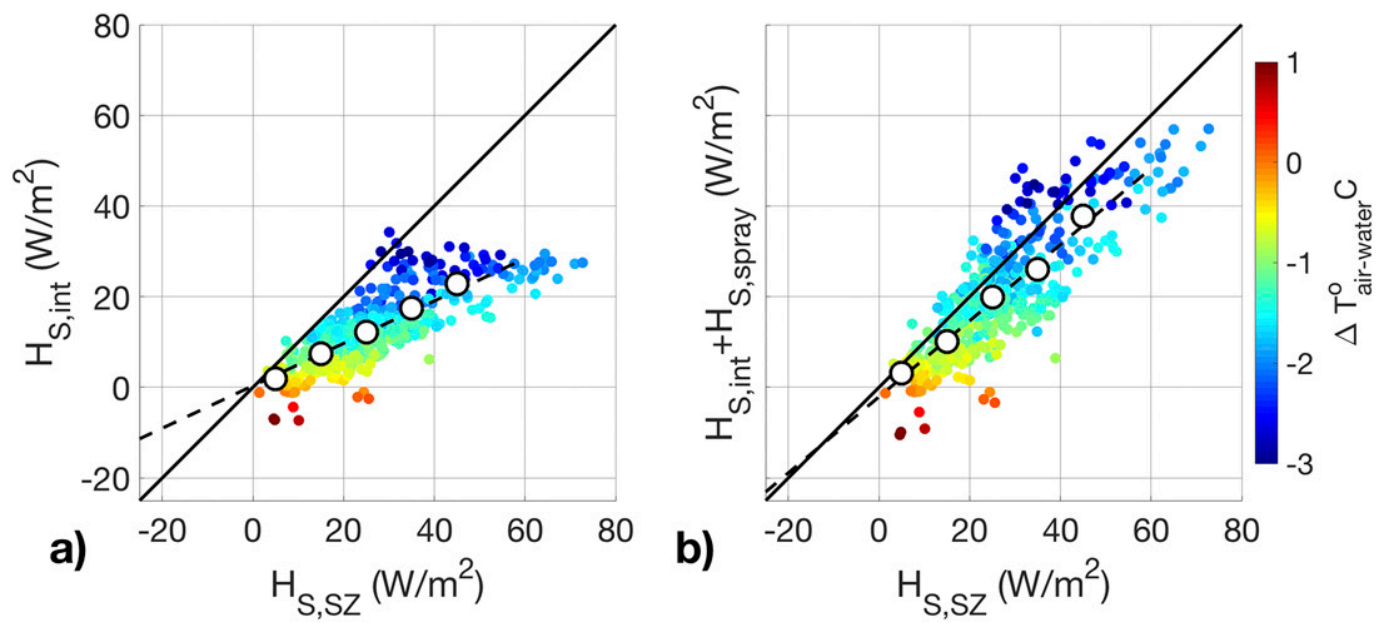

FIG. 7. (a) The $H_{S, \text { Sz }}$ observations compared with COARE3.5 $H_{S \text {,int }}$ [Eq. (2)]. (b) The $H_{S, \text { Sz }}$ observations

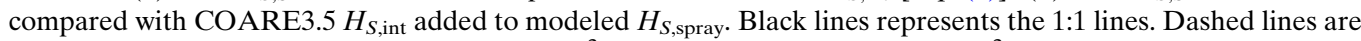
the linear regression lines, where $m=0.46$ and $r^{2}=0.63$ in (a) and $m=0.84$ and $r^{2}=0.7$ in (b). The white circles represent the average of $10 \mathrm{~W} \mathrm{~m}^{-2}$-wide bins. The dot color represents the difference in $T_{\text {air }}$ relative to $T_{\text {water }}$ with the color scale on the right. 


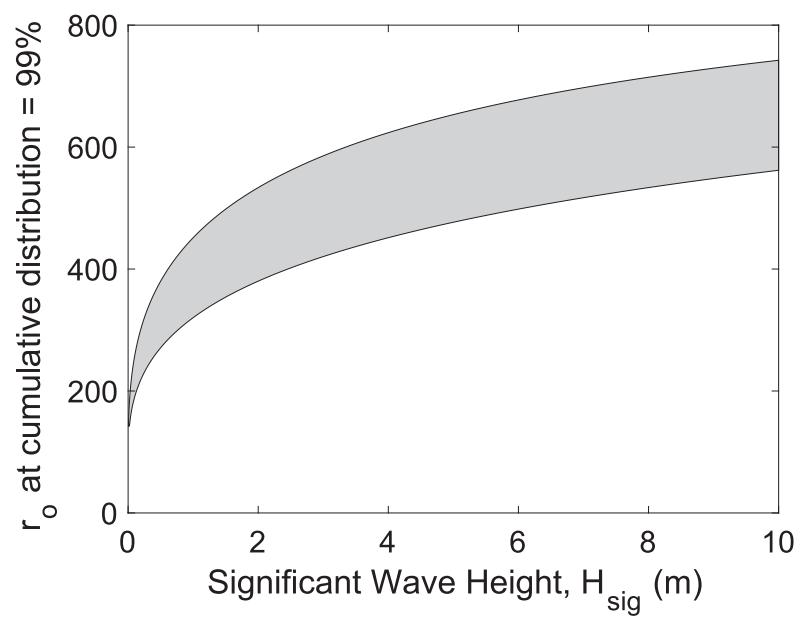

FIG. 8. The $r_{o}$ value at which the cumulative distribution of [1 $\left.\exp \left(\tau_{f} / \tau_{T}\right)\right] f_{V}\left(r_{o}\right)$ is greater than or equal to 0.99 for the Andreas (2016) modification as a function of $0.5 H_{\text {sig }} \leq h \leq 2 H_{\text {sig }}$ (gray band), with $T_{a}=14^{\circ} \mathrm{C}$.

back into the water almost immediately in front of the wave; many of these larger droplets would not be measured $75 \mathrm{~m}$ shoreward at an elevation of $8.7 \mathrm{~m}$ above mean sea level, and are not expected to be included in the Andreas (2016) spectral values. Therefore, it is expected that the Andreas (2016) slope of the SSGF tail for the spume droplet spectrum $r_{o}>100 \mu \mathrm{m}$ is too steep at $r_{o}^{-6.32}$.

The spectral shape for the spume region $r_{o}>100 \mu \mathrm{m}$ varies between SSGF models proportional to from $r_{o}^{-3}$ to $r_{o}^{-8}$. Ortiz-Suslow et al. (2016) optically measured the vertical distribution of spume droplets just above the breaking waves under hurricane-force winds in a wave tank. Their observed droplet radii ranged from 80 to $1400 \mu \mathrm{m}$. Veron et al. (2012) obtained similar results in a wave tank at high wind speeds. Both experiments observed SSGF radius dependence ranging from $r_{o}^{-3}$ to $r_{o}^{-5}$ for the larger spume droplets. Interestingly, the observed Ortiz-Suslow et al. (2016) spectra are at least qualitatively self-similar in shape at all wind speeds.

The $H_{S \text {,spray }}$ model is calibrated with measurements by increasing the tail slope of the SSGF to $r_{o}^{-4.4}$ (Fig. 3), which increases the amount of spume droplets. The combined calibrated $H_{S \text {,spray }}$ with the modeled COARE3.5 $H_{S \text {,int }}$ then match the measured values of $H_{S}$. The revised slope in the spume region of the revised SSGF is similar to the slopes measured just above the waves under simulated hurricane winds by Veron et al. (2012) and Ortiz-Suslow et al. (2016). Therefore, the amount of spume generated even under small to moderate depth-limited wave breaking in the surfzone is comparable to the spume generated by high winds over the ocean.

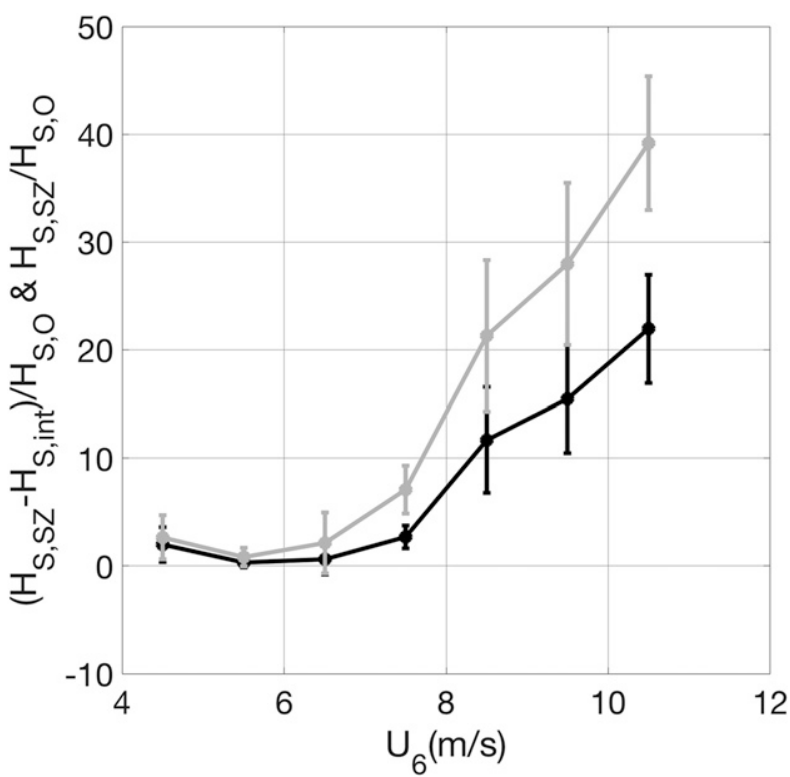

FIG. 9. Measured surfzone sensible heat flux divided by measured open ocean $H_{S, O}$ (gray line) and surfzone spray-mediated sensible heat flux (black line) computed by subtracting the COARE3.5-modeled $H_{S \text {,int }}$ [Eq. (2)] from the measured $H_{S, \text { sZ }}$ divided by $H_{S, \mathrm{O}}$. The ratio is binned in $1 \mathrm{~m} \mathrm{~s}^{-1}$ intervals. Confidence intervals are provided for $95 \%$ significance.

Another source of uncertainty is the driving mechanism expressed as a function of the average breaking wave dissipation $D$ given by the van Eijk et al. (2011) formulation, which is based on field measurements over the limited range of $r_{o}=0.2-10 \mu \mathrm{m}$. The curved shape of the van Eijk et al. (2011) $g(D)$ ranges in slope between $D^{1}$ and $D^{3}$ as compared with the $D^{3 / 4}$ dependence in the Chomka and Petelski (1997) formulation.

A third source of possible error is in calculating the average breaking wave dissipation. Neele et al. (1998) applied the model by Chomka and Petelski (1997) that parameterizes the SSGF on average breaking wave dissipation. The total wave dissipation is reasonably well described. However, they note that the average is dependent on how the width of the surfzone is calculated. They used a formulation for $D$ similar to the application here, which defines the surfzone width as the distance between where the maximum modeled breaking wave height occurs to the shoreline. Chomka and Petelski (1997) defined the outer limit as where dissipation is equal $0.003 \mathrm{~W} \mathrm{~m}^{-2}$ that results in a much wider surfzone and concomitant decrease in the average dissipation.

Observations of spray droplets generated in the surfzone at levels below the peak of the breaking wave are required to better estimate $H_{S}$. The impact of the surfzone as a conduit for releasing heat into the atmosphere is currently underestimated. The ratio of measured 

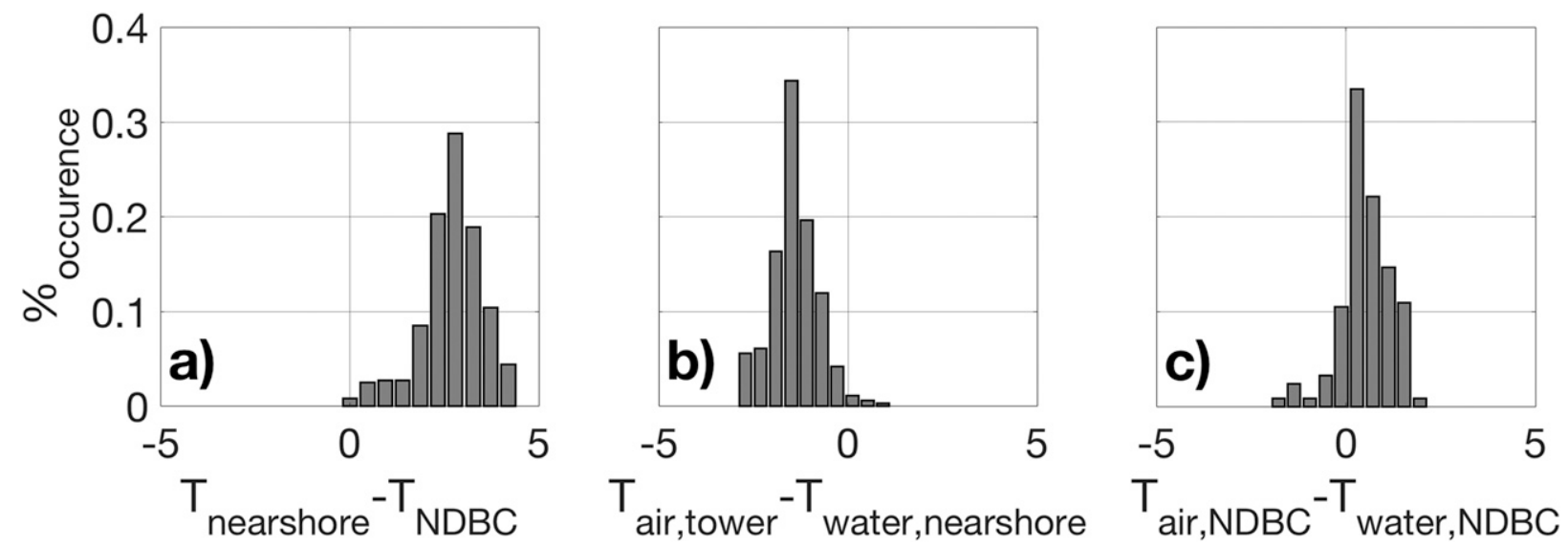

FIG. 10. Histograms of surface temperature differences $\left({ }^{\circ} \mathrm{C}\right)$ : (a) nearshore (10-m depth) water minus NDBC water; (b) air at tower minus nearshore water; (c) air NDBC minus water NDBC. The location of the NDBC buoy is shown in Fig. 1.

surfzone $H_{S, \mathrm{SZ}}$ to measured open ocean $H_{S, \mathrm{O}}$ as a function of wind speed is shown in Fig. 9. Whereas the interfacial heat flux contribution is dependent on the air-seawater surface temperature difference that varies by location and was either positive or negative, the spray-mediated surfzone heat flux was always positive and dependent on breaking wave height. The spray-only-mediated $H_{S, \text { SZ-spray }}$ is estimated by subtracting $H_{S \text {,int }}$ (COARE3.5) from $H_{S, \mathrm{SZ}}$ measured and is compared with $H_{S, \mathrm{O}}$ in Fig. 9. The ratios are similar for low wind speeds but increase by an order of magnitude by wind speed $8 \mathrm{~m} \mathrm{~s}^{-1}$.

The increasing large ratio of the surfzone interfacial heat flux to open ocean sensible heat flux is primarily owing to an average $3^{\circ} \mathrm{C}$ warmer seawater surface temperature in the nearshore (10-m depth) when compared with offshore temperature measured at the National Data Buoy Center (NDBC) buoy (Fig. 10). The average difference in the tower air temperature with the nearshore surface water temperature is $-2^{\circ} \mathrm{C}$ resulting in mostly unstable conditions. However, at the NDBC buoy offshore, the air-surface water temperature differences are mostly positive resulting in stable conditions on average. The differences in the open ocean and nearshore temperature differences are due to oceanographic surface conditions forced by the wind and alongshore currents, and is the topic of ongoing research.

The surface area of Monterey Bay is $O\left(600 \mathrm{~km}^{2}\right)$ (Fig. 1, inside dashed white line). The surfzone surface area assuming a 50-m width for Monterey Bay is $O\left(7 \mathrm{~km}^{2}\right)$ giving a ratio of Monterey Bay surfzone-ocean areas of 1:90. Applying the 20:1 ratio (Fig. 9) to the area ratio suggests that $H_{S, \mathrm{SZ}}$ represents $O(20 \%)$ of the Monterey Bay sensible heat flux estimate. This suggests that the surfzone has a potential contribution to the sensible heat flux that has not been previously considered. This will differ for different regions based on air and water temperature differences and waves.

\section{Summary and conclusions}

Surfzone sensible heat flux $\left(H_{S, \mathrm{SZ}}\right)$ obtained through direct eddy-covariance estimates was measured at four different sandy beach sites along Monterey Bay. The $H_{S, \text { Sz }}$ source region is estimated from a footprint probability distribution function (pdf) model and is only considered when at least $70 \%$ of the footprint pdf occupies the surfzone. The $H_{S, \mathrm{Sz}}$ measured are 2 times the modeled interfacial sensible heat $\left(H_{S \text {,int }}\right)$ using COARE3.5. The $H_{S, \text { Sz }}$ is associated with larger seaspray droplet production owing to depth-limited wave breaking. A formulation for estimating sensible heat flux from spray droplets $\left(H_{S \text {,spray }}\right)$ is developed based on self-similar spectra of spray droplet radii measured from the surfzone (Andreas 2016) forced by the average depth-limited breaking wave dissipation across the surfzone (van Eijk et al. 2011) to describe the generation of sea-spray droplet radii ranging $0.1<r_{o}<1000 \mu \mathrm{m}$. However, it is shown that the size of the spume droplets that contribute to $H_{S \text {,spray }}$ is limited to approximately $700 \mu \mathrm{m}$ even for the largest waves owing to the relatively short residence time in air as the droplets fall to the sea surface. Combining surfzone-modeled $H_{S \text {,spray }}$ with the COARE3.5 $H_{S \text {,int }}$ underestimates the measured surfzone $H_{S, \mathrm{Sz}}$ by $21 \%$, highlighting the importance of depth-limited wave-breaking processes to sensible heat flux. By increasing the slope of the tail of the SSGF, the modeled $H_{S \text {,spray }}$ values are increased to match the measured $H_{S, \mathrm{Sz}}$. Measured $H_{S, \mathrm{sz}}$ values are an order 
of magnitude larger than simultaneous open ocean observations. Although more work is required to improve the model, the measurements highlight the importance of the surfzone spray-mediated $H_{S, \mathrm{SZ}}$ contribution.

Acknowledgments. This work is dedicated to the memory of Edward L Andreas who indirectly inspired this manuscript from his many publications on spray. This work was supported as part of the Office of Naval Research Coastal Land Air Sea Interaction (CLASI) pilot experiment (N0001417WX00612; N0001417WX01138). Appreciation is extended to the NPS CLASI field team (Darin Keeter, Paul Jessen, Keith Wyckoff, Mathias Roth, and Tucker Freismuth) and CLASI collaborators (University of Miami: Brian Haus, Hans Graber, Dave Ortiz-Suslow, and Neil Williams; Naval Postgraduate School: Dick Lind and Ryan Yamaguchi; and Naval Research Laboratory: Jim Doyle and David Flagg). The authors thank reviewer Elisa Canepa and the anonymous reviewer whose constructive critical comments resulted in an improved manuscript.

\section{REFERENCES}

Andreas, E. L, 1989: Thermal and size evolution of sea spray droplets. CRREL Rep. 89-11, 47 pp., http://www.dtic.mil/dtic/ tr/fulltext/u2/a210484.pdf.

- 1990: Time constants for the evolution of sea spray droplets. Tellus, 42B, 481-497, https://doi.org/10.3402/tellusb.v42i5.15241.

, 1992: Sea spray and the turbulent air-sea heat fluxes. J. Geophys. Res., 97, 11 429-11441, https://doi.org/10.1029/ 92JC00876.

_ 1995: The temperature of evaporating sea spray droplets. J. Atmos. Sci., 52, 852-862, https://doi.org/10.1175/1520-0469 (1995) $052<0852$ :TTOESS $>2.0$. CO; 2 .

- 2005: Approximation formulas for the microphysical properties of saline droplets. Atmos. Res., 75, 323-345, https:// doi.org/10.1016/j.atmosres.2005.02.001.

_ 2010: Spray-mediated enthalpy flux to the atmosphere and salt flux to the ocean at high winds. J. Phys. Oceanogr., 40, 608619, https://doi.org/10.1175/2009JPO4232.1.

- 2016: Sea spray generation at a rocky shoreline. J. Appl. Meteor. Climatol., 55, 2037-2052, https://doi.org/10.1175/ JAMC-D-15-0211.1.

— , and B. Murphy, 1986: Bulk transfer coefficients for heat and momentum over leads and polynyas. J. Phys. Oceanogr., 16, 1875-1883, https://doi.org/10.1175/1520-0485(1986)016<1875: BTCFHA $>2.0 . \mathrm{CO} ; 2$.

_- and J. DeCosmo, 1999: Sea spray production and influence on air-sea heat and moisture fluxes over the open ocean. Air-Sea Exchange: Physics, Chemistry and Dynamics, G. L. Geernaert, Ed., Atmospheric and Oceanographic Sciences Library, Vol. 20, Springer, 327-362.

, L. Mahrt, and D. Vickers, 2015: An improved bulk air-sea surface flux algorithm, including spray-mediated transfer. Quart. J. Roy. Meteor. Soc., 141, 642-654, https://doi.org/ 10.1002/qj.2424.
Aubinet, M., T. Vesala, and D. Papale, 2012: Eddy Covariance: A Practical Guide to Measurement and Data Analysis. Springer Science and Business Media, $451 \mathrm{pp}$.

Battjes, J. A., 1974: Surf similarity. Proc. 14th Conf. on Coastal Engineering, Copenhagen, Denmark, ASCE, 466-480.

Chomka, M., and T. Petelski, 1997: Modeling the sea aerosol emission in the coastal zone. Oceanologia, 39, 211-225.

Clarke, A. D., S. R. Owens, and J. Zhou, 2006: An ultrafine sea-salt flux from breaking waves: Implications for cloud condensation nuclei in the remote marine atmosphere. J. Geophys. Res., 111, D06202, https://doi.org/10.1029/2005JD006565.

Dean, R. G., and R. A. Dalrymple, 1984: Water Wave Mechanics for Engineers and Scientists. Prentice-Hall, $353 \mathrm{pp}$.

de Leeuw, G., F. P. Neele, M. Hill, M. H. Smith, and E. Vignati, 2000: Production of sea spray aerosol in the surf zone. J. Geophys. Res., 105, 29397-29409, https://doi.org/10.1029/ 2000JD900549.

Derakhti, M., and J. T. Kirby, 2014: Bubble entrainment and liquidbubble interaction under unsteady breaking waves. J. Fluid Mech., 761, 464-506, https://doi.org/10.1017/jfm.2014.637.

Fairall, C. W., J. D. Kepert, and G. J. Holland, 1994: The effect of sea spray on surface energy transports over the ocean. Global Atmos. Ocean Syst., 2, 121-142.

— E. F. Bradley, D. P. Rodgers, J. B. Edson, and G. S. Young, 1996: Bulk parameterization of air-sea fluxes for Tropical Ocean-Global Atmospheric Coupled-Ocean Response Experiment. J. Geophys. Res., 101, 3747-3764, https://doi.org/ 10.1029/95JC03205.

MacMahan, J., 2017: Increased aerodynamic roughness owing to surfzone foam. J. Phys. Oceanogr., 47, 2115-2122, https:// doi.org/10.1175/JPO-D-17-0054.1.

_ , and Coauthors, 2010: Mean Lagrangian flow behavior on an open coast rip channeled beach: A new perspective. Mar. Geol., 268, 1-15, https://doi.org/10.1016/j.margeo.2009.09.011.

Monahan, E. C., 1995: Coastal Aerosol Workshop Proceedings. Naval Research Laboratory Rep. NRL/MR/7542-95-7219, 138 pp.

— D. E. Spiel, and K. L. Davidson, 1986: A model of marine aerosol generation vie whitecaps and wave disruption. Oceanic Whitecaps and Their Role in Air-Sea Exchange Processes, E.C. Monahan and G. Mac Miocaill, Eds., D. Reidel, 167-174.

_ A. Staniec, and P. Vlahos, 2017: Spume drops: Their potential role in air-sea gas exchange. J. Geophys. Res. Oceans, 122, 9500-9517, https://doi.org/10.1002/2017JC013293.

Neele, F. P., G. de Leeuw, J. Martijn, and M. Stive, 1998: Quantitative assessment of surf-produced sea spray aerosol. Propagation and Imaging through the Atmosphere II, L. R. Bissonnette, Ed., International Society for Optical Engineering (SPIE Proceedings, Vol. 3433), https://doi.org/10.1117/ 12.330242 .

Ortiz-Suslow, D. G., B. K. Haus, S. Mehta, and N. J. M. Laxgue, 2016: Sea spray generation in very high winds. J. Atmos. Sci., 73, 3975-3995, https://doi.org/10.1175/JAS-D-15-0249.1.

Piazzola, J., G. Tedeschi, and A. Demoisson, 2015: A model for the transport of sea-spray aerosols in the coastal zone. Bound.-Layer Meteor., 155, 329-350, https://doi.org/10.1007/s10546-014-9994-3.

Thornton, E. B., and R. T. Guza, 1983: Transformation of wave height distribution. J. Geophys. Res., 88, 5925-5938, https:// doi.org/10.1029/JC088iC10p05925.

Tuller, S. E., 1972: Energy balance microclimatic variations on a coastal beach. Tellus, 24, 260-270, https://doi.org/10.1111/ j.2153-3490.1972.tb01552.x.

van Eijk, A. M. J., J. T. Kusmierczyk-Michulec, M. J. Francius, G. Tedeschi, J. Piazolla, D. L. Merritt, and J. D. Fontana, 2011: 
Sea-spray aerosol particles generated in the surf zone.

J. Geophys. Res., 116, D19210, https://doi.org/10.1029/ 2011JD015602.

Veron, F., 2015: Ocean spray. Annu. Rev. Fluid Mech., 47, 507-538, https://doi.org/10.1146/annurev-fluid-010814-014651.

—- C. Hopkins, E. L. Harrison, and J. A. Mueller, 2012: Sea spray spume droplet production in high wind speeds. Geophys. Res. Lett., 39, L16602, https://doi.org/10.1029/ 2012GL052603.
Vignati, E., G. deLeeuw, and R. Berkowicz, 2001: Modeling coastal aerosol transport and effects of surf-produced aerosols on processes in the marine atmospheric boundary layer. J. Geophys. Res., 106, 20 225-20 238, https://doi.org/10.1029/ 2000JD000025.

Wan, Z.-H., J.-B. Zhu, K. Sun, and K. Zhou, 2017: An integrated turbulent simulation and parameter modeling study on seaspray dynamics and fluxes. Ocean Eng., 130, 64-71, https:// doi.org/10.1016/j.oceaneng.2016.11.041. 